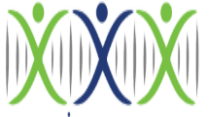

iRASD

Pakistan Journal of Humanities and Social Sciences

Volume 9, Number 3, 2021, Pages 328-339

SCIENCES (P.JSS

Journal Homepage:

https://journals.internationalrasd.org/index.php/pjhss

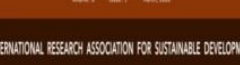

\title{
Impact Evaluation of Agriculture Technology Adoption: A Primary Data Analysis
}

\author{
Muhammad $\mathrm{Ali}^{1}$, Adiqa Kausar Kiani ${ }^{2}$, Kashif Raza ${ }^{3}$ \\ ${ }^{1}$ PhD Scholar, Department of Economics, Federal Urdu University of Arts, Science \& Technology (FUUAST), Islamabad, \\ Pakistan. Email: m_aliqamar@yahoo.com \\ 2 Associate Professor, Department of Economics, Federal Urdu University of Arts, Science \& Technology (FUUAST), \\ Islamabad, Pakistan \& Future Technology Research Centre, YUNTECH, Taiwan. Email: adiqa.kiani@fuuast.edu.pk \\ ${ }^{3}$ Lecturer, Department of Economics, The Islamia University of Bahawalpur, Pakistan. Bahawalnagar Campus \\ Email: kashif.raza@iub.edu.pk
}

\section{ARTICLE INFO}

\section{Article History:}

Received:

Revised:

Accepted:

November 27, 2021

December 03, 2021

Available Online: December 05, 2021

\section{Keywords:}

Technology Index

Average Treatment Effects

Logistic Approach

Propensity Score

\section{ABSTRACT}

The primary objective of the study is the assessment and impact evaluation of improved and new agriculture technology adoption on farmers' income levels in the region (Faisalabad). There are seven technologies used in the study to assess technology adoption impact. A micro panel primary data (206-07 \& 2018-19) has been used. The propensity score is estimated and matched for average treatment effects (ATE) to analyze the income effect. The assessment of technology adoption is observed using the logistic approach for pooled data. The technology poverty index is used to measure the level of farmer technology adoption rate. The results indicate that these technologies have a positive and significant role in farmers' poverty and income level in the study area. The used improved technologies for the current showed positive and significant role in the farmers' income determination. These agriculture technologies have an important role in increasing farmer income and welfare in the study area. The study recommends that more incentives be announced to develop and promote improved technologies for adoption. The provision of these technologies may increase farmers' income level as well as food security by engaging in other income-generating activities.

(C) 2021 The Authors, Published by iRASD. This is an Open Access Article under the Creative Common Attribution Non-Commercial 4.0

Corresponding Author's Email: m_aliqamar@yahoo.com

\section{Introduction}

Agriculture plays an important role in sustainable development. It also reduces poverty and solve food security issues in developing country. Agriculture sector is key sector in Pakistan for growth, poverty reduction and reducing food security issues. But this sector is not performing satisfactory over the last few years due to which poverty and unemployment increased as we compare it with other regions in the world. The population of the country has increasing trend and specific to Punjab. There is increasing trend of food demand due to increasing in population. It is the need of the current era to increase agriculture productivity. For this purpose, the new and improved agriculture technologies to be implemented to increase agriculture productivity. The new and improved agriculture technology means the way of increasing production at minimum input. These technologies will also lead toward employment opportunities for rural community and poverty reduction as well.

The district Faisalabad is the third largest city of Pakistan and contributing its role in the economy of Punjab as well Pakistan. The district is famous for its industrial role as well as agriculture performance in the economy of the country. Its role in GDP was almost $\$ 43$ billion in 2013 but it is expected that it will increase to $\$ 87$ billion in 2025 at a growth rate of 5.7 percent. It contributes over 5 percent toward Pakistan' annual GDP. The district average GDP is $\$ 20.55$ billion of which 21 percent from agriculture sector. It has also various agriculture research institutes contributing to the economy of Pakistan by introducing new and improved 
agriculture technologies. The current study selected this district due to its importance in agriculture sector in Punjab as well as in overall economy. The agriculture technologies used in the study are improved seed technology, farm mechanization, water irrigation technology, fertilizer usage technology, improved electricity technology, internet/social media access technology and mobile phone technology.

The primary objective of the study is the assessment and impact of these technologies by using technology index and propensity score matching method on household income effect and marginal effects. Further, the study also compares technology adoption in the region. Faisalabad district has eight towns and the current study randomly selected two tehsils namely, Chak Jhumra and Sammundri.

The previous studies conducted in developing countries identified single or two technologies adoption determinants. The studies used cross section data primary or secondary to assess the potential factors responsible for its adoption. There is hardly any study used multiple technologies adoption and its determinants by using panel data (base year, end line). The current study fills this gap by using micro panel data (base year 2006-07 \& end line 201819) by using seven different technologies to identify the impact of these technologies on farmer income. The study has investigated the intensities of each technology separately for each year to assess the change in both years base year 2006-07 and 2018-19 as end-line.

Agriculture technology adoption leads toward higher yield and farmer income level. The study has used seven agricultural technologies adoption in the district Faisalabad, Pakistan. A technology index has been constructed for each year to assess the adoption rate of each technology. The study has investigated the impact of these technologies on farmer income level during base year (2006-07) and end line (2018-19) respectively. The impact evaluation of each year is estimated separately. Agriculture technology adoption leads toward higher yield and farmer income level. The study has used seven agricultural technologies adoption in the district Faisalabad, Pakistan. A technology index has been constructed for each year to assess the adoption rate of each technology. The study has investigated the impact of these technologies on farmer income level during base year (2006-07) and end line (2018-19) respectively. The impact evaluation of each year is estimated separately.

The previous studies conducted in developing countries identified single or two technologies adoption determinants (Mwangi \& Kariuki, 2015). The studies used cross section data primary or secondary to assess the potential factors responsible for its adoption. There are no or very few studies used multiple technologies adoption and its determinants by using panel data (base year, end line). The current study fills this gap by using micro panel data (base year 2006-07 \& end line 2018-19) by using more than two technologies (seven technologies) to identify the impact of these technologies on farmer income. It has been investigated the intensities of each technology separately for each year to assess the change overtime for 2006-07 and 2018-19 respectively. There are eight towns in the district Faisalabad. These are Chak Jhumra, Lyallpur, Jinnah, Iqbal, Samundari, Jaranwala, Madina and Tandlianwal. The randomly selected tehsils are Chak Jhumra and Samundri are shown in Figure 1. 
Figure 1: Tehsil/Towns of Faisalabad District



\section{Literature Review}

There are various studies conducted worldwide to check the impact of agriculture technology adoption on social welfare, income, and production of relevant crops. Most of the studies conducted across the globe caters one or the other technology adopted in specific region. The studies used both primary and secondary data to assess the impact of agriculture technologies on different indicators. These studies mostly used time series or cross-sectional data. A very few studies conducted based upon panel data to assess the change and impact on different indicators, but they depend limited agriculture technologies adoption.

The studies conducted on technology adoption reveals that the use of new agricultural technology such as high yielding varieties leads toward increase in a country productivity as can be analyzed under Green Revolution. The adoption of these improved technologies leads toward subsistence agriculture productivity to higher level and agro-industrial economy (Fao, 2014).

The agriculture productivity has reduced while poverty increased in recent era due to which it is necessary to adopt new and improved technology to boost productivity in the country. The study applied a double-hurdle model 1 based upon ten-year panel household data collected in Kenya. The study examined the determinants of fertilizer adoption level and its intensity. The results shows that age, education level, credit facility, presence of a cash crop, distance to fertilizer market and agro-ecological potential are statistically significant with impact on fertilizer adoption. The major influencing factors are gender level, dependency ratio, credit facility, presence of cash crop status, distance to extension service and agro ecological potential. The study also suggested that the main factors to increase fertilizer usage adoption in the country are improving access to agricultural credit for low-income farmers, efforts to promote fertilizer usage among farmers, government investment in rural areas, efficient port facilities and low distributing cost (Olwande, John, Sikei, Geophrey, Mathenge, 2009).

The study reveals that training has an important role in technology adoption as well as productivity or yield over time. They used five-year panel data in Tanzania by applying spatial econometric techniques fond that non-trained farmers learned new techniques from the trained ones through social networks. They found that paddy yield increased from 3.1 tons per

\footnotetext{
${ }^{1}$ Deals with an individual's decision level on the extent of participation in an activity is the result of two process (hurdle with zero type, extent of participation that individual is no zero types).
} 
hector to 4.7 tons per hectare of trained farmers while non-trained farmers yield increased from 2.6 tons per hectare to 3.7 tons per hectare that indicates that trainings has important role in yield and productivity enhancement (Nakano et al., 2015).

The impact of improved rice varieties adoption on rice productivity has been investigated. The study is based upon sample data of 481 by considering welfare impact in Nigerian country. The improved seed access has significant role in such technology adoption. The non-adopters found to be higher poverty level as compared to adopters. The study has used counterfactual outcomes to assess the consistency of impact estimates. By using the instrumental variable methodology, the study found impact of improved seed varieties on productivity and household welfare. The improved seed adoption has positive and significant impact on productivity and household expenditures that leads toward improved living standards the farmers. The pre-requisite for improved seed adoption is improved seed accessibility to increase productivity and reduce poverty in the country (Awotide et al., 2012). The study is based upon improved soybean seed adoption in Malawi by using plot level data of 1237 samples to assess the productivity and income effects. By using stochastic dominance analysis, the study results shows that the yields and net crop income is higher for adopters while lower of non-adopters. The endogenous switching regression model shows that the improved varieties adoption is associated with an average of 61 percent yield gain while 53 percent income gain (Manda et al., 2019).

The knowledge gap is also an important determinant in technology adoption rate. The study reveals that only focusing on yield is misleading because technology is widely used in the country which has no yield impact. Three waves of panel data used for the study to estimate correlated random coefficient model. It further calculated returns to improved seed varieties yields, costs, and profits. The study found that comparative advantage had no significant role while economic measures of returns was more relevant in explaining technology adoption decisions (Michler et al., 2019).

The media (television, radio, mobile phone) also plays an important role in providing information and awareness to farmers in time and may increase agriculture productivity, and farmers' prosperity. The use of mobile phone has strong evidence of getting information related to commodity price and market information well in time. The farmers using mobile phone can easily get information of various markets across regions and arrange transportation accordingly. The study reveals timely information availability has impact on productivity. The study is based upon 60 farmers from the district Charsada, Pakistan. The study reveals that low communication cost and availability of information about wholesale price rate and low calling cost has positive impact on production and marketing respectively (Jehan et al., 2014).

Zimbabwe is considered as semi-arid with higher poverty level, low rural income and low agriculture productivity with food insecurity which leads toward difficulties in sustainability. They have investigated the relationship between agriculture technology use and agriculture productivity with food security among households. The study by using 55 stratified random sampling household's data found conservative agriculture technology significant higher yields among smallholders' farmers. While on the other hand, the t-test shows significant impact of irrigation technology adoption yields among farmers who adopted this technology (Muzari et al., 2013).

The study has investigated the adoption level and welfare impacts of multiple technologies in Zambia. The study used panel data and multinomial endogenous switching regression. The multinomial endogenous switching effect model reveals that joint adoption of multiple agricultural technologies has greater impacts on yield, household income level and poverty reduction impact than individual technology adoption. The study recommends adopting multiple agricultural technologies adoption for its better impact. Further the adoption to be accompanied of improved support service to enhance yield, income level and poverty reduction in the country (Khonje et al., 2018).

The study used three round random sampled data and reveals that consumption expenditure level, income level, and asset per capital of the households increased across the survey years. The participated household in the survey shows significant positive impact on consumption expenditure level and calorie per adult but not the income and asset per capita. 
The study recommends that provision of package must be accompanied as per local endowment level, focus on youth, widowed and divorced households with prioritize (Teka \& Lee, 2020).

\section{Methodology and Data}

The study conducted among farmers using or not using agriculture technologies in the district Faisalabad. Faisalabad has an important role in Pakistan economy because it contributes to the GDP as well as its agriculture sector playing important role. The randomly selected tehsils namely, Chak Jhumra and Samundri. The data collected from two randomly selected tehsils; Chak Jhumra and Samundri consisting of 720 farmers in each round (base line 2006-07) and end line (2018-19) respectively. In the first stage two tehsils selected using probability sampling by using structured questionnaire. The second stage involves simple random sampling of selected villages from each tehsil of farmers based on the number in each village. The randomly selected farmers from each village were 60 . The total random sample farmers were 1420 of base line 720 and end line 720 .

Semi-structure questionnaire developed based upon previous literature. The questionnaire consists of farmers' socio-economic, demographic, income, education level and specific to agriculture technologies usage recoded in both rounds. There are seven agriculture technologies considered in this study. First, the technology index is constructed and then based upon this index, the role of these technologies upon farmer income is analyzed. The data has been gathered through a survey of farm households. The study is based on farm household data collected from 12 villages from 02 tehsils of Faisalabad district Faisalabad. The major crops are mostly grown in these areas. A sample survey of a total of 1440 households from 12 villages was conducted during base year 2005-06 and end year 2018-19 respectively. Information on household characteristics, land, labour, major crops being grown in the area, agriculture technologies used in the region, input used, crop production technologies and household income related information were collected during the survey which was implemented in 02 phases using structured pre-tested questionnaires. The survey is based upon interviews as well as Focus Group Discussion in the region to collect information and agriculture technologies. The farm level data and information were collected by the lead author accompanied with trained enumerators. The stratified random sampling technique was used for household selection (Wang et al., 2010; Wu et al., 2010). The random sample twelve villages selected for survey and interviews for both tehsils Chak Jhumra and Samundri. These villages are Barnala, Khachiean, Naliawala, Bhattian, Jahllaran, Raghbirpura, Kishanpura, Hargobind, Siraj, Bhart and Haryal in Table 1.

\section{Table 1: Demographic Profile of Sampled Villages}

\begin{tabular}{|c|c|c|c|c|c|c|c|}
\hline \multirow[b]{2}{*}{ Sr. No. } & \multirow[b]{2}{*}{ Sampled Villages } & \multicolumn{2}{|c|}{1998} & \multicolumn{2}{|c|}{2017} & \multicolumn{2}{|c|}{ Change (1998-2017) } \\
\hline & & Population & $\begin{array}{l}\text { Number of } \\
\text { Houses }\end{array}$ & Population & $\begin{array}{c}\text { Number of } \\
\text { Houses }\end{array}$ & Population & $\begin{array}{c}\text { Number of } \\
\text { Houses }\end{array}$ \\
\hline $\mathbf{I}$ & $103 \mathrm{JB}$ & 5829 & 931 & 7212 & 1152 & $23.7 \%$ & $23.7 \%$ \\
\hline II & 106-JB & 3654 & 572 & 5670 & 887 & $55.2 \%$ & $55.2 \%$ \\
\hline III & 109-JB & 1965 & 267 & 3089 & 420 & $57.2 \%$ & $57.2 \%$ \\
\hline IV & $20-J B$ & 2987 & 455 & 3062 & 466 & $2.5 \%$ & $2.5 \%$ \\
\hline $\mathbf{v}$ & 23-JB & 6152 & 731 & 6318 & 943 & $2.7 \%$ & $29.0 \%$ \\
\hline VI & 467-JB & 968 & 136 & 699 & 98 & $-27.8 \%$ & $-27.8 \%$ \\
\hline VII & $468-G B$ & 4362 & 646 & 5419 & 803 & $24.2 \%$ & $24.2 \%$ \\
\hline VIII & $470-\mathrm{GB}$ & 5501 & 735 & 8762 & 1309 & $59.3 \%$ & $78.1 \%$ \\
\hline IX & 472-GB & 2631 & 348 & 3649 & 482 & $38.7 \%$ & $38.7 \%$ \\
\hline $\mathbf{x}$ & $168-G B$ & 2756 & 372 & 3268 & 441 & $18.6 \%$ & $18.6 \%$ \\
\hline $\mathbf{X I}$ & 438-GB & 2048 & 274 & 2396 & 377 & $17.0 \%$ & $37.6 \%$ \\
\hline XII & 463-GB & 4472 & 704 & 9007 & 1418 & $101.4 \%$ & $101.4 \%$ \\
\hline \multicolumn{2}{|c|}{ Total (Chak Jhumra Villages) } & 21555 & 3091 & 26050 & 3966 & $20.9 \%$ & $28.3 \%$ \\
\hline \multirow{2}{*}{\multicolumn{2}{|c|}{$\begin{array}{l}\text { Total (Samundri Villages) } \\
\text { Change (\%age)-1998-2017 }\end{array}$}} & 21770 & 3079 & 32501 & 4830 & $49.3 \%$ & $56.9 \%$ \\
\hline & & & & & & $35.1 \%$ & $42.6 \%$ \\
\hline
\end{tabular}

Source: 1998 \& 2017 Population Census, Bureau of Statistics (BSP), Pakistan

The demographic profile of selected villages reveals that there is increase of almost 35.1 percent in population size while 42.6 percent in number of houses as shown in the table. The population size of tehsil Chak Jhumra has increased to 20.9 percent while 28.9 percent in number of houses while 49.3 percent population size increase and 56.9 percent number of houses in tehsil Samundri respectively. 
Table 2 presents technology adoption rate in the district Faisalabad. It shows that there is positive change over time from 2006-07 to 2018-19. The adoption of improved seed technology has increase from 9.4 percent to 475.0 percent respectively. The farm mechanization technology also improved from 28.6 percent to 57.5 percent while water irrigation technology from 14.3 to 46.9 percent respectively. The fertilizer adoption technology also improved from 46.9 percent to 85.0 percent while access to improved electricity provision 10.6 to 82.1 percent for irrigation purpose. The internet or social media access improved but not so significant as from 5.0 percent to 28.1 percent while mobile phone adoption increased significantly from 3.2 percent to 87.5 percent respectively.

Table 2: Adoption Level of Technology

\begin{tabular}{|c|c|c|c|c|c|c|c|}
\hline $\begin{array}{l}\text { Sr. } \\
\text { No. }\end{array}$ & Technology & $\begin{array}{c}\text { Adopters } \\
\text { Level }\end{array}$ & $\begin{array}{l}\text { \% Of Non- } \\
\text { Adopters } \\
\text { 2006-07 }\end{array}$ & Total & $\begin{array}{c}\text { \% Of } \\
\text { Adopters }\end{array}$ & $\begin{array}{l}\text { \% Of Non- } \\
\text { Adopters } \\
\text { 2018-19 }\end{array}$ & Total \\
\hline $\mathbf{I}$ & Improved Seed Technology & $68(9.4)$ & $652(90.6)$ & 720 & $342(47.5)$ & $378(52.5)$ & 720 \\
\hline II & $\begin{array}{c}\text { Farm Mechanization } \\
\text { Technology }\end{array}$ & $206(28.6)$ & $514(71.4)$ & 720 & $414(57.5)$ & $306(42.5)$ & 720 \\
\hline III & $\begin{array}{c}\text { Water Irrigation } \\
\text { Technology }\end{array}$ & $103(14.3)$ & 617 (85.7) & 720 & $338(46.9)$ & $382(53.1)$ & 720 \\
\hline IV & Fertilizer Usage Technology & $338(46.9)$ & $382(53.1)$ & 720 & $612(85.0)$ & $108(15.0)$ & 720 \\
\hline $\mathbf{v}$ & $\begin{array}{c}\text { Improved Electricity } \\
\text { Technology }\end{array}$ & $76(10.6)$ & $644(89.4)$ & 720 & $591(82.1)$ & 129 (17.9) & 720 \\
\hline VI & $\begin{array}{c}\text { Internet/social media } \\
\text { Technology }\end{array}$ & $36(5.0)$ & $684(95.0)$ & 720 & $202(28.1)$ & 518 (71.9) & 720 \\
\hline VII & Mobile Phone Technology & $23(3.2)$ & $697(96.8)$ & 720 & $630(87.5)$ & $90(12.5)$ & 720 \\
\hline
\end{tabular}

Source: Author Primary data

\section{Econometric Modeling of Adoption and Impact}

The current study deals with impact evaluation of agriculture technology adoption upon farmer income and welfare based upon panel data collected from field. The field data collected in 2006-07 as baseline while follow up (end line) survey in 2018-19. The technology poverty index constructed based upon PSM method of ATE. There are two approaches widely used for impact evaluation. These approaches are experimental and non-experimental. In this paper, we have applied propensity score matching technique for impact evaluation.

\subsection{Propensity-Score Matching Technique}

This method or technique is an important for impact evaluation and widely used in various studies (Rosenbaum \& Rubin, 1983). This method is quasi-experimental method by using various statistical techniques. The artificial control group is designed by matching each treated unit with non-treated unit of similar characteristics. The outcome variable for treated group cannot be observed for with and without project. It is necessary for control group identification to draw what would have happened to the beneficiaries without project.

On the other hand, the outcome variable of treated group is unobservable for with and without project. It is necessary for control group identification to infer the impact on beneficiaries without project. A group of farmers whether unit of production or agriculture household are needed that are statistically similar in all observed characteristics to those who are statistically similar in all observed characteristics to those who receive the project. In propensity score matching method, the problem can be resolved by estimating the conditional probability of receiving the project $(\mathrm{Pi}=1)$ while given a vector of observed characteristics $(\mathrm{X})$ (dimensionality problem) that can be "aggregated" into one number or score as follows:

$\operatorname{Pr}\left(P_{i}\right)=\operatorname{Pr}\left(P_{i}=1 \mid X\right)$

The equation can be estimated through probit or logit model. The vector of covariates is possible to be composed of those characteristics that determine project placement to replicate the selection process. The institutional arrangements required that define selection into project to determine these characteristics (Caliendo \& Kopeinig, 2008). To apply propensity score matching technique, two conditions are needed that are conditionally independence assumption (CIA) while the second one is the overlap condition. The proper control group is necessary to be identified so that two conditions hold, and $X$ vector of covariates is observable by the researcher, and it can be used to estimate project impact as follows: 
$\mathrm{Yi}=$ describes outcome for the treated;

$Y j=$ describe outcome for the non-treated;

$t=1$ represents post-treatment period while $P=1$ describes project participation; and $P=0$ represents non-participation.

The advantage of propensity score matching method is that it facilitates the identification of a counter factual when the selection bias to be addressed is clearly due to observable characteristics of the farmers. It is not only affective and appropriate when unobservable farmers' characteristics affect both the outcome variables and the program placement. In this situation, we would use both approaches DD and PSM to remove bias (Lopez \& Maffioli, 2008).

\subsection{Index Construction}

An index is a set of rules or criteria that govern an index creation, calculation, and maintenance. There are large number of studies used index for their studies. The adoption index has been used for different dimensions of agricultural technologies in India (Rajni, Arora, 2009). The other studies used adoption index whose values varies from 0 to 100 depending upon the degree of adoption of new agriculture technology by farmers (Mishra et al., 2018). The adoption index is used in agroforestry system in India to represent the system at different scales (Singhal et al., 2019). The same methodology has been used for technology adoption index for this study. The agriculture technology adoption index has been constructed for both years 2006-07 and 2018-19 respectively.

\subsection{Technology Index (TI)}

The technology Index has been calculated based upon seven technologies used in the current study. All seven technologies have been used as in binary form that whether a farmer has adopted a specific technology or not. If a farmer is using a technology, he has been given 1 and if not using then equal to 0 . The Technology Index formula is given as follows:

For Technology Index (TI) each technology adopter has been assigned 1 and 0 if he is not using a particular technology. It means, technology index has seven number, and the adopters has been assigned number as per its adoption level.

Or

$$
T I=\frac{(I S A+F M A+W I T A+F U A+\text { AIEA }+I S M A A+M P A A)}{\text { No of Technologies }}-----(3)
$$

$$
T I=\frac{(1+1+1+1+1+1+1)}{7}=\frac{7}{7}=1-------(4)
$$

Where, TI is Technology Index, ISA is Improved/Hybrid Seed Adoption, FMA is Farm Mechanization Adoption, WITA is Water Irrigation Technologies Adoption, FUA is Fertilizer Usage Adoption, AIEA is Access to Improved Electricity Adoption, ISMAA is Internet/Social Media Access Adoption and MPAA is Mobile Phone Access Adoption.

\subsection{Technology Poverty Index (TPI)}

The Technology Poverty Index (TPI) has been calculated to measure the level of technology adoption of local farmers in the Faisalabad district. A farmer is technological poor if its score is:

$0.40(40 \%)$ or less than $(40 \%)$

The technology poverty level is in binary form and explained as follows:

A farmer is non-poor if its value is $0.40(40 \%)$ and treated as 1

A farmer is poor if its value is less than $0.40(40 \%)$ and treated as 0

The outcome variable used is based upon technology poverty index in PSM for ATE. 


\subsection{Household Income Effects}

In impact evaluation of agriculture technology, the study has explored the impact of agriculture technology on farmer income. The empirical evidence reveals that there are positive and significant role of technology adoption on farmer income level (Tesfaye et al., 2016). The impact of agriculture technology adoption has been estimated by using logistic approach. The income impact of technology adoption has been estimated for both periods (2006-07 \& 2018-19) respectively to determine the level and impact on household income. The following model have been estimated for household income effect:

$$
Y_{i}=\beta_{0}+\beta_{1} I S A+\beta_{3} F M A+\beta_{6} W I T A+\beta_{8} F U A+\beta_{8} A I E A+\beta_{8} I S M A+\beta_{8} M P A A+\text { Error-- (5) }
$$

Where, $Y_{i}$ represents farmer income from agriculture of three major crops (Wheat, Sugarcane, and Rice), if the farmer has used agriculture technologies, then 1 and 0 otherwise.

The independent variables are seven technologies being used by the farmers.

ISA Improved Seed adoption equal to 1,0 for non-adaptors

FMA Farm Mechanization Adoption equal to 1, 0 otherwise

WITA Water Improved Technologies Adoption equal to 1, 0 otherwise

FUA Fertilizer Usage Adoption equal to 1, 0 otherwise

AIEA Access to Improved Electricity Adoption equal to 1,0 otherwise

ISMA Internet/social media Access equal to 1,0 otherwise

MPAA Mobile Phone Adoption Access equal to 1, 0 otherwise

\section{Estimation and Results}

The logistic Propensity Score Matching (PSM) technique for Average Treatment Effects (ATE) and Farmer Income effects of agriculture technology adoption have been investigated. Further, the study has also explored the marginal effects of technology adoption in income determination.

\subsection{Propensity Score Matching (PSM) Method}

Propensity Score Matching (PSM) method has been used to estimate the Average Treatment Effects of agriculture technology adoption in the Faisalabad area. A separate Propensity Score Matching method has been investigated for each technology and for each year (2006-07 \& 2018-19) respectively. The Table 2 presents the results obtained through this approach. The results obtained during base year 2006-07 indicates that Water Irrigation Technologies Adoption (WITA), Fertilizer Usage Adoption, Access to Improved Electricity Adoption (AIEA) and Internet/Social Media Access Adoption has positive significant importance in our approach. These technologies increase the technology poverty level of farmers if a farmer is not using technology. It means that farmer technology poverty level is strongly attached with these technologies adoption rate. We have used Technology Poverty level as outcome variable for our analysis in all cases. The treatment variable used for the analysis is technology adoption level. The treatment independent variables used for the analysis are age of farmer, family size, farmer education and family member employment status. The WITA and AIEA are positive significant at 10 percent level while FUA is positive significant at 1 percent level. The FUA and AIEA also have positive and significant role in reducing technology poverty level.

The end line or follow up year 2018-19 indicate that all these seven technologies have positive and significant role in technology poverty level for not adopting these technologies. The results shows that all these technologies increase technology poverty level who are not adopting for these technologies. The technology poverty index is indirectly linked with poverty level because as usage of technology reduces, the farmer income level decreases that leads toward increasing poverty level. All these seven technologies have role in poverty level. The improved/hybrid seed adoption technology, farm mechanization, water irrigation technology and fertilizer usage have positive impact on technology poverty level that leads toward reducing poverty level in the district Faisalabad. On the other hand, improved electricity adoption, internet/social media access and mobile phone access also positive and significant role in reducing poverty in the region. 
On the other hand, the pooled data shows that all these seven technologies have also positive and significant role in influencing technology poverty level in the area. It indicates that these technologies have an important role in technology poverty level among farmers in the area. The pooled data results show that overall, these technologies intensify technology poverty level in the area who are lack of or not using these technologies. Our results investigated that these technologies are necessary for farmer welfare and technology poverty level to improve over time.

\section{Table 2: Propensity Score Matching Estimation}

\begin{tabular}{lccl}
\multicolumn{1}{c}{ Agriculture Technologies (ATE) } & $\mathbf{2 0 0 6 - 0 7}$ & $\begin{array}{c}\mathbf{2 0 1 8 - 1 9} \\
\text { Coefficients }\end{array}$ & $\begin{array}{l}\text { Pooled } \\
\text { Improved/Hybrid Seed Adoption (ISA) }\end{array}$ \\
& 0.063 & $0.083^{* * *}$ & $0.693^{* * *}$ \\
& 0.027 & 0.028 & 0.016 \\
Farm Mechanization Adoption (FMA) & 0.026 & $0.107^{* * *}$ & $0.446^{* * *}$ \\
& 0.109 & 0.026 & 0.027 \\
Water Irrigation Technologies Adoption (WITA) & $0.196 *$ & $0.110^{* * *}$ & $0.669^{* * *}$ \\
& 0.101 & 0.020 & 0.016 \\
Fertilizer Usage Adoption (FUA) & $0.061^{* * *}$ & $0.177^{* * *}$ & $0.521^{* * *}$ \\
& 0.014 & 0.049 & 0.026 \\
Access to Improved Electricity Adoption (AIEA) & $0.196 *$ & $0.217^{* * *}$ & $0.706^{* * *}$ \\
Internet/Social Media Access Adoption (ISMAA) & 0.101 & 0.047 & 0.020 \\
& $0.156 * * *$ & $0.081^{* * *}$ & $0.547^{* * *}$ \\
Mobile Phone Access Adoption (MPAA) & 0.029 & 0.014 & 0.023 \\
\end{tabular}

Source: Author Own Estimation Results for 2006-07 \& 2018-19 (end-line), the values in each variable represents coefficient and standard error with significance level (*10\%,**5\%,*** 1\%)

\subsection{Income Effects}

The logistic model 2006-07 results show the positive significant impact of technology adoption on farmer income level. The Access to Improved Electricity has negative significant impact. On the other hand, marginal effects shows that Farm Mechanization Adoption (FMA), Fertilizer Usage Adoption (FUA), Access to Improved Electricity Access (AIEA) has significant impact on farmer income determination in the district, Faisalabad, Pakistan during this period. Farm Mechanization Adoption and Fertilizer Usage Adoption (FUA) has significant positive impact on farmer income determination during 2006-07 while Access to Improved Electricity Adoption (AIEA) negatively affects farmer income level. It indicates that the base period (2006-07) has no significant positive impact of technology adoption in farmer income determination due to low or less technology adoption in the district.

The results of 2018-19 (end-line) show that ISA, FMA, FUA, IEAA and ISMAA have positive significant role in farmer income determination in the district Faisalabad. The empirical studies narrate that improved seed adoption has positive and significant impact on farmer income level (Tesfaye et al., 2016). In the current study we have estimated logistic model to investigate impact of adoption improved seed technology on farmer income. There is no positive significant impact found during 2006-07 while there is positive significant role in farmer income determination during 2018-19 (1\%). While marginal effects also have positive significant impact on farmer income level. There is increase of 12.5 percent income level as one percent increase improved seed adoption in the area.

Farm Mechanization Adoption (FMA) has also important role in farmer income determination. The results shows that there is no significant its role in income determination, but it has marginal role in income determination as shown in Table 1 . The end line period (2018-19) explores that it has positive and significant role (1\%) in farmer income determination. Marginal effects also confirm this relationship but not significant. Water Irrigation Technologies Adoption (WITA) is an improved and new agriculture technologies mostly using in developed and developing countries but there still exist lack of its usage in developing country. Our study finds out the relationship with farmer income. It has insignificant negative relation with income level during 2006-07 while positive insignificant relation with farmer income level but the marginal effects have positive significant relation with farmer income level. 
The Fertilizer Usage Adoption (FUA) of recommended usage in crop has positive relation with farmer income level. The current study finds out positive significant (1\%) relation with farmer income level during 2018-19 while positive insignificant during base period (2006-07). If there is increase of its adoption by one percent, the farmer income rises by 71.8 during 2018-19. The Access to Improved Electricity Adoption (AIEA) has negative insignificant relation with farmer income during 2006-07 while positive significant relation with farmer level during 2018-19 respectively. If there is change in one unit, there is change of 0.975 farmer income level during 2018-19. The logistic results shows that there is positive significant relation with farmer income during end line period 2018-19 while negatively insignificantly during base period 206-07. If there is change of its adoption, the income level changes by 0.376 during 2018-19 while during base period 2006-07, it is negatively insignificantly affected farmer income level.

The marginal effects estimation shows that when there is change of this technology adoption, farmer level income changes by .0 .093 positively. While during base period 2006-07, it has negatively insignificantly with farmer income. The Mobile Phone Access Adoption (MPAA) has negative insignificant relation with farmer income level during both period base period and end line (2006-07 \& 2018-19) respectively. The marginal effects estimation relates negative significant its effects on farmer income level as indicated in results table. The overall logistic results indicate that improved seed farm mechanization, fertilizer usage, access to improved electricity, internet/social media has important and positive role in farmer income level specifically during end line period 2018-19 in the region (Faisalabad, Pakistan).

Table 3: Logistic Model Income Effects and Marginal Effects (2006-07 \& 2018-19)

\begin{tabular}{|c|c|c|c|c|}
\hline \multirow[b]{2}{*}{ Agriculture Technologies } & \multicolumn{2}{|c|}{ 2006-07 } & \multicolumn{2}{|c|}{ 2018-19 } \\
\hline & Coefficients & $\begin{array}{c}\text { Marginal } \\
\text { Effects }\end{array}$ & Coefficients & $\begin{array}{c}\text { Marginal } \\
\text { Effects }\end{array}$ \\
\hline Improved/Hybrid Seed Adoption (ISA) & $\begin{array}{l}0.316 \\
0.386\end{array}$ & 0.064 & $\begin{array}{l}0.509 * * * \\
0.181\end{array}$ & $0.125^{*}$ \\
\hline Farm Mechanization Adoption (FMA) & $\begin{array}{l}1.842 \\
0.202\end{array}$ & $0.415^{*}$ & $\begin{array}{l}0.761 * * \\
0.386\end{array}$ & 0.166 \\
\hline Water Irrigation Technologies Adoption (WITA) & $\begin{array}{l}-0.37 \\
0.343\end{array}$ & -0.082 & $\begin{array}{l}0.115 \\
0.178\end{array}$ & $0.029 *$ \\
\hline Fertilizer Usage Adoption (FUA) & $\begin{array}{l}0.097 \\
0.269\end{array}$ & $0.024 *$ & $\begin{array}{l}0.718^{* * * *} \\
0.267\end{array}$ & 0.150 \\
\hline Access to Improved Electricity Adoption (AIEA) & $\begin{array}{l}-2.25 * * * \\
0.302\end{array}$ & $-0.48 *$ & $\begin{array}{l}0.975^{* *} \\
0.403\end{array}$ & 0.183 \\
\hline Internet/Social Media Access Adoption (ISMAA) & $\begin{array}{c}-0.066 \\
0.453\end{array}$ & -0.014 & $\begin{array}{c}0.376^{*} \\
0.193\end{array}$ & $0.093^{*}$ \\
\hline Mobile Phone Access Adoption (MPAA) & $\begin{array}{c}-0.314 \\
0.536\end{array}$ & -0.070 & $\begin{array}{c}-0.381 \\
0.288\end{array}$ & $-0.095^{*}$ \\
\hline Constant & $\begin{array}{l}-0.205 \\
0.414\end{array}$ & - & $\begin{array}{l}0.408 \\
0.507\end{array}$ & - \\
\hline
\end{tabular}

Source: Author Own Estimation Results for 2006-07 \& 2018-19, the values in each variable represents coefficient and standard error with significance level (*10\%,** 5\%,*** $1 \%)$

\section{Conclusion and Policy Recommendations}

The aim of this paper is to assess and evaluate the impact of agriculture technologies adoption in the district Faisalabad, Pakistan. For this purpose, we have used base year (200607 ) and end line (follow up) survey 2018-19. We have set a panel data set of both year with 720 farmers in each round of same respondents. There are significance difference of adopters and non-adopters in the area. It indicates that the implementation of econometric methods is necessary to identify the factors responsible to increase its severity in the area. We have calculated technology poverty index for farmers to indicate the level of adoption. The technology poverty index is used as outcome variable in Propensity Score Matching (PSM) method for Average Treatment Effects (ATE).

The government policies regarding improved or new agriculture technologies are prerequisite to increase its adoption rate to boost this sector for food security and employment generation. There are many farmers are still less or not using these technologies in the area that needs to be convinced and trained to adopt these technologies to improve their living standard and welfare. The results show that technology poverty level was higher during base year (2006-07) while it has reduced to some extent in end line survey 2018-19 but there still exist low level of these technologies adoption in the area. The Propensity Score Matching (PSM) approach to estimate Average Treatment Effects (ATE) indicate that these seven 
technologies have an important and significant role in farmer technology poverty level in the area. The results indicate that if a farmer is not using these technologies, it intensifies technology poverty level in the area. The results suggest that there are needs to increase its adoption rate to reduce technology poverty level in the district Faisalabad, Pakistan.

The results of income or welfare effects of technology adoption indicate that the adoption has significant role in determining farming income level in the region. The base year period (2006-07) indicates that no exist any positive significant role of these technologies due to lack of or less adoption rate in the region. While the end line survey (2018-19) shows positive and significant role in farmer income determination. Improved/Hybrid Seed Adoption, Farm Mechanization Adoption, Fertilizer Usage Adoption, Access to Improved Electricity Adoption and Internet/Social Media Access Adoption has positive and significant role in farmer income determination in the district. These technologies are playing an important role in increasing farmer income and welfare in the area. These technologies are main influencing in farmer income determination (Beyene et al., 2020). The study suggest that new and improved technologies has positive impact on household income level by generating employment opportunities and will reduce poverty level.

\section{References}

Awotide, B. A., Diagne, A., \& Omonona, B. T. (2012). Impact of Improved Agricultural Technology Adoption on Sustainable Rice Productivity and Rural Farmers' Welfare in Nigeria: A Local Average Treatment Effect (LATE) Technique. African Economic Conference.

Beyene, T., Mulugeta, W., \& Merra, T. (2020). Technical efficiency and impact of improved farm inputs adoption on the yield of haricot bean producer in Hadiya zone, SNNP region, Ethiopia. Cogent Economics \& Finance, 8(1), 1833503. https://doi.org/10.1080/23322039.2020.1833503

Caliendo, M., \& Kopeinig, S. (2008). Some practical guidance for the implementation of propensity score matching. Journal of Economic Surveys, 22(1), 31-72. https://doi.org/10.1111/j.1467-6419.2007.00527.x

Fao. (2014). A regional rice strategy for sustainable food security in Asia and the Pacific Final edition. www.fao.org/publications

Jehan, N., Aujla, K. M., Shahzad, M., Hussain, A., Zahoor, M., Khan, M., \& Bilal, A. (2014). Use of mobile phones by farming community and its impact on vegetable productivity. Pakistan Journal of Agriculture Research, 27(1), 58-63.

Khonje, M. G., Manda, J., Mkandawire, P., Tufa, A. H., \& Alene, A. D. (2018). Adoption and welfare impacts of multiple agricultural technologies: evidence from eastern Zambia. Agricultural Economics, 49(5), 599-609. https://doi.org/10.1111/agec.12445

Lopez, F., \& Maffioli, A. (2008). Technology Adoption, Productivity and Specialization of Uruguayan Breeders: Evidence from Impact Evaluation. Office of Evaluation and Oversight Working Papers OVE/WP-07/08 (Inter-American Development Bank, Washington, DC, 2008), February, 1-37.

Manda, J., Alene, A. D., Tufa, A. H., Abdoulaye, T., Wossen, T., Chikoye, D., \& Manyong, V. (2019). The poverty impacts of improved cowpea varieties in Nigeria: A counterfactual analysis. World Development, 261-271. https://doi.org/10.1016/j.worlddev.2019.05.027

Michler, J. D., Tjernström, E., Verkaart, S., \& Mausch, K. (2019). Money matters: The role of yields and profits in agricultural technology adoption. American Journal of Agricultural Economics, 101(3), 710-731. https://doi.org/10.1093/ajae/aay050

Mishra, P. K., Upadhyay, R. G., \& Upadhyay, A. D. (2018). Diagnostic Analysis of Technology Adoption and Factors Influencing Adoption Level of Tribal Farmers of Madhya Pradesh. Economic Affairs, 63(1), 1-07. https://doi.org/10.30954/0424-2513.2018.00150.1

Muzari, W., Kupika, O., Danha, C., \& Mapingure, C. (2013). The impacts of agricultural technology use on productivity and food security among smallholder farmers in Zimbabwe: The case of Makonde district. Journal of Agricultural Extension and Rural Development, 5(10), 225-231. https://doi.org/10.5897/JAERD2013.0503

Mwangi, M., \& Kariuki, S. (2015). Factors Determining Adoption of New Agricultural Technology by Smallholder Farmers in Developing Countries. Journal of Economics and Sustainable Development Www.Iiste.Org ISSN, 6(5). www.iiste.org

Nakano, Y., Tsusaka, T. W., Aida, T., \& Pede, V. O. (2015). The Impact of Training on 
Technology Adoption and Productivity of Rice Farming in Tanzania: Is Farmer-to-Farmer Extension Effective?

Olwande, John, Sikei, Geophrey, Mathenge, M. (2009). Agricultural Technology Adoption: A Panel Analysis of Smallholder Farmers' Fertilizer use in Kenya John Olwande. In Center of Evaluation for Global Action, Agriculture for Development (Issue January 2009).

Rajni, Arora, R. (2009). A Novel Adoption Index of Selected Agricultural Technologies: Linkages with Infrastructure and Productivity. Agricultural Economics Research Review, 22(June), 109-120.

Rosenbaum, P. R., \& Rubin, D. B. (1983). The central role of the propensity score in observational studies for causal effects. Biometrika, 70(1), 41-55. https://doi.org/10.1093/biomet/70.1.41

Singhal, V., Bhat, S. S., Ahmad, S., \& Mir, N. H. (2019). Development of adoption index: A proxy measure for assessing the adoption rate of agroforestry practices in Indian context Development of adoption index: A proxy measure for assessing the adoption rate of agroforestry practices in Indian context. International Journal of Chemical Studies, 7(January), 1900-1903.

Teka, A., \& Lee, S. K. (2020). Do agricultural package programs improve the welfare of rural people? Evidence from smallholder farmers in ethiopia. Agriculture (Switzerland), 10(5). https://doi.org/10.3390/agriculture 10050190

Tesfaye, S., Bedada, B., \& Mesay, Y. (2016). Impact of improved wheat technology adoption on productivity and income in Ethiopia. African Crop Science Journal, 24(1), 127. https://doi.org/10.4314/acsj.v24i1.14s

Wang, H., Pandey, S., Hu, F., Xu, P., Zhou, J., Li, J., Deng, X., Feng, L., Wen, L., Li, J., Li, Y., Velasco, L. E., Ding, S., \& Tao, D. (2010). Farmers' Adoption of Improved Upland Rice Technologies for Sustainable Mountain Development in Southern Yunnan. Https://Doi.Org/10.1659/MRD-JOURNAL-D-09-00012.1, 30(4), 373-380. https://doi.org/10.1659/MRD-JOURNAL-D-09-00012.1

Wu, H., Ding, S., Pandey, S., \& Tao, D. (2010). Assessing the Impact of Agricultural Technology Adoption on Farmers' Well-being Using Propensity-Score Matching Analysis in Rural China. Asian Economic Journal, 24(2), 141-160. https://doi.org/10.1111/J.1467-8381.2010.02033.X 